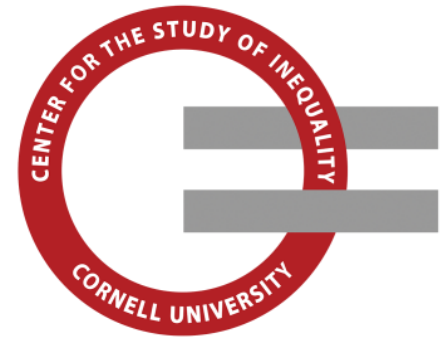

Center for the Study of Inequality

Cornell University

363 Uris Hall

Ithaca, NY 14850

(607)254-8674

inequality@cornell.edu

www.inequality.cornell.edu

\title{
Occupational Plans, Beliefs about Educational Requirements, and Patterns of College Entry
}

Stephen L. Morgan

Cornell University

Theodore S. Leenman

Harvard University

Jennifer J. Todd

Kentucky University

Kim A. Weeden

Cornell University

Final version published as: Morgan, Stephen L., Theodore S. Leenman, Jennifer J. Todd, and Kim A. Weeden. 2013. "Occupational Plans, Beliefs about Educational Requirements, and Patterns of College Entry." Sociology of Education 86(3): 197-217. (http://journals.sagepub.com/doi/pdf/10.1177/0038040712456559).

Copyright: Final version (C) 2013 American Sociological Association. This preprint is provided with permission of the publisher.

This article is brought to you free and open access by the Center for the Study of Inequality Collection in eCommons@ cornell.edu.

Follow this and additional works at: https://ecommons.cornell.edu/handle/1813/52084 


\title{
Occupational Plans, Beliefs about Educational Requirements, and Patterns of College Entry
}

\author{
Stephen L. Morgan', Theodore S. Leenman', Jennifer J. Todd ${ }^{3}$, and \\ Kim A. Weeden ${ }^{1}$
}

\begin{abstract}
In this article, a measure of students' beliefs is constructed from three sources of information on 12,509 high school seniors from the Education Longitudinal Study (2002 to 2006). First, verbatim responses to questions on occupational plans, drawn from restricted-access data records, are coded into I,220 categories to capture detailed information (specific job titles), extended information (the listing of multiple jobs), and contradictory information (the listing of multiple jobs with divergent characteristics). Second, the educational requirements of detailed jobs, as specified in the U.S. Department of Labor's Occupational Information Network database, are matched to all jobs that students list within their verbatim occupational plans. Third, student perceptions of the educational requirements of their planned jobs, which were revealed in response to a follow-up question posed immediately after they provided their verbatim occupational plans, are used to identify students with puzzling beliefs about their educational and occupational trajectories. The authors then show that (I) students who are categorized as having uncertain and/or inaccurate beliefs about the educational requirements of their expected jobs have lower rates of college entry than those with certain and accurate beliefs, and (2) among entrants, these same students have lower rates of immediate college enrollment and lower attendance at four-year colleges.
\end{abstract}

After seven decades of empirical research in sociology, much still remains contested in our collective effort to build a consensus model of educational attainment. ${ }^{1}$ Central to current disagreements are the relative importance of purposive deliberation, socialization through reflected appraisals, and adaptation to structural constraints. Each has been marshaled to account for the behavior of prospective college students from different social origins, and each has received some, but not definitive, empirical support.

In this article, we engage a recent literature on college entry decisions that combines mechanisms for belief formation with models of decision making in specific social contexts. We evaluate whether the uncertainty and inaccuracy of students' beliefs determine a substantial portion of the variation in the educational decisions they enact in subsequent years. To do so, we analyze the relationships between occupational plans, the objective educational requirements of those plans, students' beliefs about these educational requirements, and subsequent patterns of postsecondary education.

\footnotetext{
'Cornell University, Ithaca, NY, USA

${ }^{2}$ Harvard University, Cambridge, MA, USA

${ }^{3}$ Kentucky Department of Education, Frankfort, USA
}

\section{Corresponding Author:}

Stephen L. Morgan, Cornell University, Department of Sociology, 323 Uris Hall, Ithaca, NY 14853, USA

Email: morgan@cornell.edu 


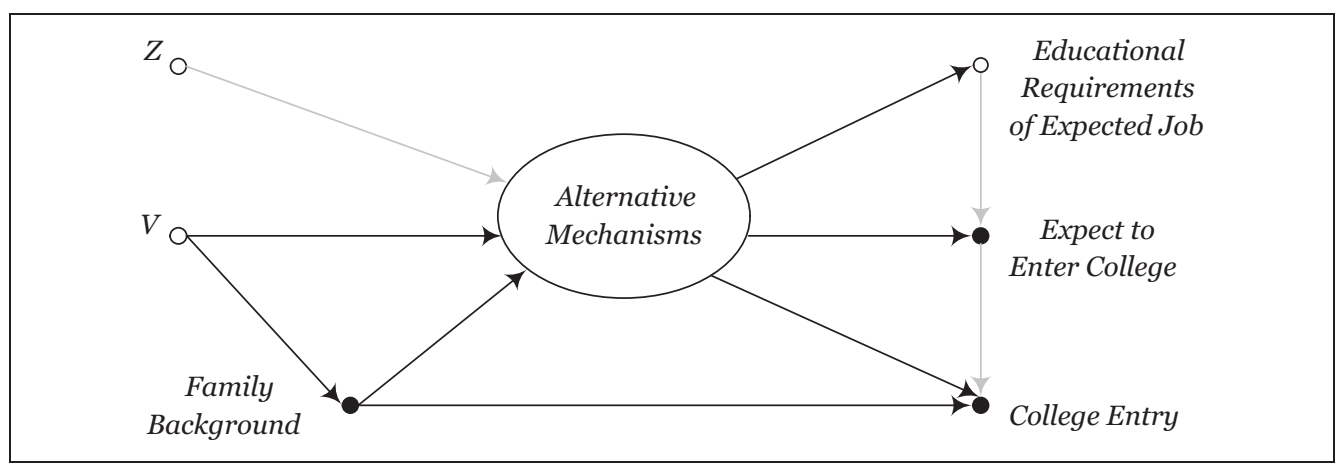

Figure I. A causal model of college entry with an unspecified mechanism

\section{Causal Claims in the Literature on Educational Attainment}

Figure 1 presents a graphical model of college entry that we use to organize a brief presentation of alternative causal mechanisms that are thought to generate patterns of college entry. ${ }^{2}$ In Figure 1, and subsequent figures, observed variables are represented by solid nodes $(\bullet)$ and unobserved variables by hollow nodes (o). Arrows represent causal effects, and no assumptions of linearity or separability are maintained. Causes can have nonlinear effects on outcomes, and causes can interact with one another in producing effects. The black arrows represent causal effects that we assume all researchers agree exist, and the gray arrows represent causal effects whose existence is under debate. Family Background represents the five standard measured variables for socioeconomic status (mother's education and occupational prestige, father's education and occupational prestige, and family income). College Entry represents three related measures of college entry patterns, all of which are analyzed in this article: entry into any postsecondary institution, entry into a postsecondary institution within six months of high school graduation (conditional on entry), and attendance at a four-year college within two years of high school graduation (also conditional on entry).

It is most efficient to frame our empirical investigation with the classic divide in the educational attainment literature between models that are centered on processes of socialization and those that are centered on deliberative choice. The most influential socialization model remains the "Wisconsin model" of status attainment (Sewell, Haller, and Portes 1969; but see the comprehensive review in Sewell et al. 2004). The mechanism at the core of the model is social influence: Significant other$\mathrm{s}$ - parents, teachers, and peers - form expectations about whether students will continue on to college, after considering the students' socioeconomic status and observed academic performance. Students are assumed to internalize these expectations as their own aspirations, which then compel the appropriate motivation that leads to alternative trajectories through the educational system.

Placed within Figure 1, significant others' influence is the primary mechanism which transmits the effect of family background into the college expectations that then determine college entry, the latter via the causal effect Expect to Enter College $\longrightarrow$ College Entry. ${ }^{3}$ The Wisconsin model's proponents recognized that other variables determined significant others' influence, some of which may be completely exogenous, as in $Z$ in Figure 1. They also allowed mental ability to be an important determinant of academic performance, assuming that unmeasured variables in $V$ generate relationships among socioeconomic status, mental ability, and academic performance. The Wisconsin model did not assume that the educational requirements of expected jobs would determine college expectations, as would be implied by the gray arrow pointing to Expect to Enter College in Figure 1 (see Duncan, Haller, and Portes 1968 for the reasoning). ${ }^{4}$

In contrast to the status socialization perspective long dominant in sociology, a strong choicetheoretic model of college entry prevails in economics. This model gives considerable powers of foresight to adolescents and to those who guide their decisions (see Comay, Melnik, and Pollatschek 1973; Keane and Wolpin 2000; Manski 1989; Manski and Wise 1983; Willis and Rosen 1979). With reference to Figure 1, current models in this tradition (see Hoxby 2004) assert that family 
background, now operationalized as family income and possibly parental education, determines college entry, along with innate and constructed ability in $V$, by way of deliberative choices. Students, with the assistance of their parents, are assumed to consider individual-specific foregone opportunity costs and lifetime earnings gains associated with alternative educational degrees. After then considering whether they have access to the resources that can be used to meet the direct costs of higher education, students choose from among alternative postsecondary education trajectories on the basis of cost-benefit differences.

In the choice-theoretic tradition, college entry expectations are noncausal and best regarded as epiphenomena of the choice process itself. They are instantaneous reflections of ongoing deliberation, and as such they are not causes of the choices that they predict. Beliefs about the educational requirements of expected future jobs are assumed to also reflect the underlying choice process, with these beliefs embedded in more general forecasts of personal labor market returns to alternative educational degrees. And, for many prospective college students, alternative postsecondary educational degrees are considered investments in general skills applicable to ranges of jobs, making beliefs about the educational requirements of specific jobs of minor importance.

A recent literature on college entry has attempted to bring socialization and choice perspectives together by articulating mechanisms through which beliefs about observable opportunities and constraints can partially determine the choices of purposively oriented students. Working at the intersection of these traditions, a number of scholars have focused on the role of information and uncertainty (see Bozick et al. 2010; Goyette 2008; Grodsky and Jones 2007; Grodsky and Riegle-Crumb 2010; Morgan 2005; Schneider and Stevenson 1999; Staff et al. 2010). Many of these researchers adopt an underlying model whereby students make purposive choices about their futures but under information deficits and with goals that are susceptible to social influence. Often students are thought to make college entry decisions while reflecting on the educational requirements of the jobs they desire. For example, in one of the most influential pieces in this recent literature, Schneider and Stevenson (1999) considered how occupational aspirations condition subsequent educational careers. They carefully considered whether adolescents maintain "aligned ambitions," which they defined as the match of concrete educational plans to the educational requirements of desired jobs. They documented how uncertainty in occupational plans can have a destabilizing effect on college and labor market entry decisions, leading to inconsistent patterns of behavior and suboptimal enrollment decisions.

In this article, we take on the empirical challenge of establishing whether and how these sorts of beliefs matter for college entry patterns. We see this task as critical to future theoretical advances in modeling educational attainment. After all, if it turns out that beliefs do not much matter, the recent literature is claiming theoretical advances that will ultimately fail to account for much additional behavior beyond that which can be explained by the models of the past, models that rely on relatively fixed and easy-to-measure attributes: the background characteristics of individuals and the objective costs and benefits of education.

\section{An Evaluative Framework}

In moving this agenda forward, we think it useful to fine-tune the model in Figure 1 to increase its specificity. For the working model in Figure 2, the ellipse for alternative mechanisms has been replaced by three unobserved variables that we posit represent the core of the mechanism that is asserted in the recent literature just referenced.

First, unmeasured information, $I$, that informs educational choices is generated by exogenous factors in $Z$ and $V$. This information, primarily about the fairness of the education system and the costs and benefits of college education, is also determined directly by family background. We assume that this effect of family background on $I$ emerges because those who occupy advantaged social positions are more comfortable searching for information beyond that already available to them because of joint structural determinants, $V$, of both family background and information. Second, beliefs, $B$, are formed on the basis of this information, although in interaction with family background. Here we assume that students from different family backgrounds may process their acquired information differently, and they may also feel (probably accurately) that the costs and benefits of education depend on their social origins. Third, performance in schooling, $P$, which we conceptualize as a broad collection of measures that constitute preparation for college (i.e., not simply observed grades and scores on standardized tests), is then determined by both beliefs and family 


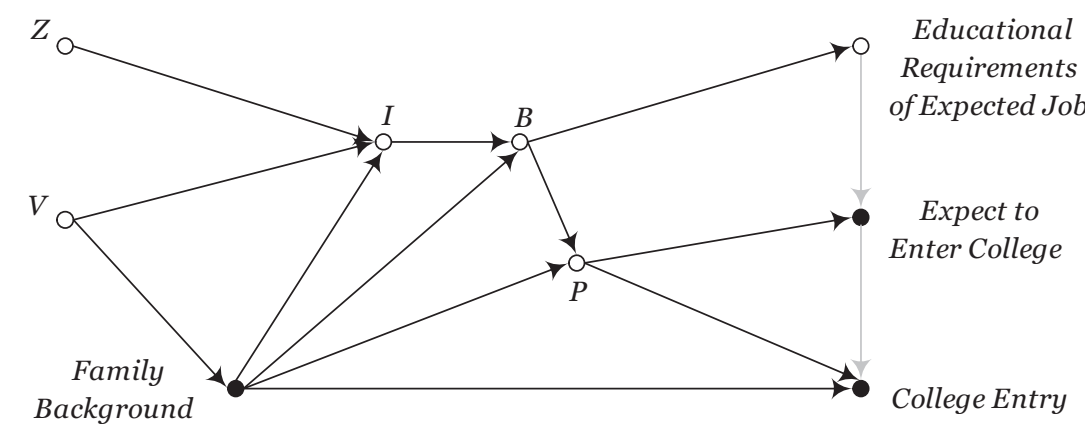

Figure 2. A working model of college entry in which information $(I)$, beliefs $(B)$, and performance $(P)$ constitute the mechanism in Figure I

background. Finally, college entry is determined, for this working model, by performance and by family background. $^{5}$

Empirical test. How can our working model help evaluate the role of beliefs? Our empirical analysis has a simple goal: to determine whether there is evidence to support the existence of the causal pathways $Z \longrightarrow I \longrightarrow B \longrightarrow P \longrightarrow$ College Entry and $V \longrightarrow I \longrightarrow B \longrightarrow P \longrightarrow$ College Entry, each of which comingles with the effects of Family Background (through the latter's interactive effects on $I, B$, and $P$ ).

The empirical challenge is that $Z, V, I, B$, and $P$ are either partly or completely unobserved. We argue, however, that one test is available, and indeed a strong test. This test rests on our unique measure of students' beliefs, which we present in full detail in the next section. Nominally, our measure captures students' beliefs about their future jobs and their beliefs about the educational requirements of their future jobs. However, our measure also captures student-level variation in the accuracy and uncertainty in these beliefs. This additional variation generates leverage that can be used to assess the importance of belief-based causal pathways.

To analyze whether these features of beliefs are consequential for college entry patterns, we first investigate two nested empirical questions:

Question 1: Do beliefs about the educational requirements of expected jobs, and any inherent uncertainty within them, predict college entry patterns?

Question 2: Do these beliefs predict college entry patterns after conditioning on family background?
If the answer to these questions is "yes," then the case for the importance of a contingent beliefbased mechanism at the heart of the college entry process has support. To foreshadow our results, we show that these unconditional and conditional associations not only exist but are quite substantial.

In our subsequent analysis, we introduce four additional empirical questions, which motivate robustness checks and further deepen our substantive interpretations. Using a diagnostic routine for causal effect heterogeneity, we show that there is very little chance that these crucial associations can be attributed to other unmeasured variables that pick up an extra dimension of family background. Second, we show that the belief-entry associations, and conditional associations, remain even after an adjustment for students' own college expectations. This result implies that a substantial portion of the belief-based prediction of college entry patterns that unfold in subsequent years is (1) unforeseen by students themselves while still in high school and (2) cannot be accounted for by traditional status socialization accounts. We conclude with models that demonstrate how performance differences by the end of high school line up with the belief-entry associations, as predicted by the causal mechanism in the working model of Figure 2.

\section{METHODS}

\section{Data and Analysis Sample}

Data were drawn from the 2002 base-year, 2004 follow-up, and 2006 follow-up waves of the Education Longitudinal Study (ELS), which is a nationally representative sample of students in public and private high schools. We analyze the 
panel sample, which includes 12,591 respondents who participated in all three rounds of the survey. We restricted the analysis to the 12,509 panel respondents who had data that were complete enough to determine whether they entered postsecondary institutions by 2006 . The data are weighted by the baseyear and second follow-up panel weight (BYF2WT; developed by the data distributors), multiplied sequentially by two estimated inverse probabilities that account for nonrandom participation in all three waves of the survey and for missing data on the variable measuring attendance at a postsecondary institution. ${ }^{6}$ The estimated probabilities were drawn from two separate logit models that predict inclusion in the panel with (1) demographic characteristics, (2) family background characteristics, and (3) base-year indicators of academic engagement.

\section{Variables and Modeling Strategy}

The variables used in this article are presented and explained as they are introduced into the analysis. Our main results are drawn from estimated logit regressions for three outcome variables on college entry patterns. We also model consequential heterogeneity within our measure of beliefs, using the diagnostic routine presented in Morgan and Todd (2008).

\section{RESULTS}

Table 1 presents the college entry patterns for ELS respondents, all of whom were high school sophomores when sampled in 2002. As shown in the first panel, 72.5 percent of sophomores entered some form of postsecondary institution by 2006 . We will refer to this group of individuals as "college" entrants, even though many of these students did not enter traditional four-year colleges. Among these college entrants, the second panel of Table 1 shows that 54.6 percent entered college immediately (which we define as having entered a postsecondary institution within six months of graduating from high school or receiving a General Educational Development certificate) and attended a four-year college by 2006 . $^{7}$ Another 31.8 percent entered postsecondary institutions immediately, but none of these students had attended four-year colleges by 2006. The remaining 13.6 percent of college entrants entered college with a delay (of more than six months) following high school graduation; of these, 10.3 percent never attended four-year colleges.
Table I. College Entry Patterns by 2006 for Students Who Were High School Sophomores in 2002 and (Mostly) High School Seniors in 2004

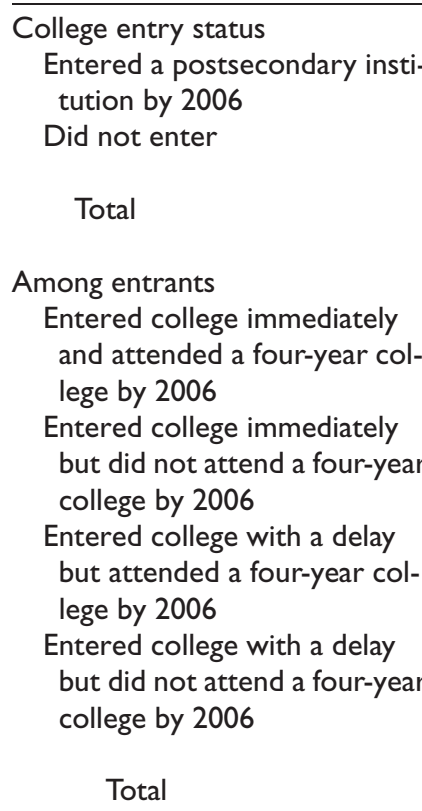

Source: Education Longitudinal Study, 2002 to 2006. Note: Data are weighted. The unweighted samples sizes for the two panels are 12,509 and 9,561.

In the next section, we first analyze college entry. Then, we offer two additional sets of models that are restricted to college entrants. The latter analyses combine the rows in the second panel of Table 1 in two ways: whether students entered postsecondary institutions immediately (rows 1 and 2 vs. rows 3 and 4) and whether entrants ever attended four-year colleges (rows 1 and 3 vs. rows 2 and 4).

\section{Beliefs about Expected Jobs and Their Educational Requirements}

Table 2 presents the educational requirements of the jobs that students listed as occupational plans in 2004, when most students were in their senior year of high school. This variable is one component of our core predictor variable, and its construction requires some explanation. Question 57 of the 2004 ELS self-administered student questionnaire instructed respondents to "write in the job or occupation that you expect or plan to have at age 30." Students then made three choices: write in 
Table 2. Beliefs about the Educational Requirements of Expected Jobs Listed for Occupational Plans in 2004

\begin{tabular}{|c|c|c|c|}
\hline & Weighted $n$ & $\begin{array}{l}\text { Weighted } \\
\text { Percentage }\end{array}$ & $\begin{array}{l}\text { Potentially Puzzling Response to } \\
\text { the Follow-up Question }\end{array}$ \\
\hline \multicolumn{4}{|l|}{$\begin{array}{l}\text { Beliefs about educational re- } \\
\text { quirements of expected jobs }\end{array}$} \\
\hline $\begin{array}{l}\text { College or more (all jobs listed } \\
\text { require at least a college } \\
\text { degree) }\end{array}$ & $6,275.1$ & 50.2 & $\begin{array}{l}16.7 \text { percent of these } \\
\text { respondents (i.e., } 8.4 \text { percent of } \\
\text { the } 50.2 \text { percent) believed that } \\
\text { a college degree was not neces- } \\
\text { sary to "get the job" }\end{array}$ \\
\hline $\begin{array}{l}\text { High school or less (all jobs } \\
\text { listed require a high school } \\
\text { degree or less) }\end{array}$ & $1,929.3$ & 15.4 & $\begin{array}{l}83.8 \text { percent of these respond- } \\
\text { ents (i.e., I } 2.9 \text { percent of the } \\
\text { I5.4 percent) believed that } \\
\text { more than a high school } \\
\text { diploma was necessary to "get } \\
\text { the job" }\end{array}$ \\
\hline $\begin{array}{l}\text { High school and college (some } \\
\text { jobs listed require a high } \\
\text { school degree or less and } \\
\text { some jobs listed require } \\
\text { a college degree or more) }\end{array}$ & 254.5 & 2.0 & \\
\hline \multicolumn{4}{|l|}{ Did not list a job: } \\
\hline $\begin{array}{l}\text { "Don't know" (selected as } \\
\text { a response) }\end{array}$ & $3,647.4$ & 29.2 & \\
\hline $\begin{array}{l}\text { Missing (no response or } \\
\text { incomplete survey) }\end{array}$ & 318.3 & 2.5 & \\
\hline Uncodable & 84.4 & 0.7 & \\
\hline Total & 12,509 & 100.0 & \\
\hline
\end{tabular}

Source: Education Longitudinal Study, 2002 to 2006.

Note: Data are weighted.

a response, select "You don't know," or skip the question. $^{8}$

The data processors contracted by the U.S. Department of Education coded responses to this prompt into an occupational plans variable with 17 categories. Each of the 17 is broadly consistent with census major occupation groups (e.g., craft, professional) categories, although with some variation: a differentiation of "professional A" and "professional B" as well as separate categories for "school teacher," "protective service," and "other." The data distributors also provided the verbatim responses to question 57 as metadata available to approved users of the restricted-access ELS data. Our analysis makes use of these verbatim responses.

After examining these verbatim responses, we concluded that (1) many of the students offered more than one occupation in their stated plans, and (2) the 17-category variable offered in the public-use data set was an exceedingly coarse representation of the available information on how students view their futures. We therefore assembled our own team to code these verbatim occupational plans into 1,220 distinct categories. We coded each job listed within the verbatim response, using an extended version of the 2000 Standard Occupational Classification and the 2002 Occupational Information Network (O*NET) database, both of which were produced by the U.S. Department of Labor. This coding allowed us to determine the educational requirements of expected jobs, as specified in the O*NET database. ${ }^{9}$

Table 2 presents our categorization of these responses after they were matched to the educational requirements of students' expected jobs. Approximately half of respondents, 50.2 percent, only listed a job or jobs that required at least 
a bachelor's degree or more of education. In contrast, 15.4 percent of respondents listed a job or jobs that all required only a high school degree or less.

Two categories of respondents expressed variably uncertain plans. First, 2.0 percent of respondents offered two or more jobs that were internally inconsistent in their educational requirements; that is, at least one job required a college degree and at least one job required no more than a high school degree. Second, 29.2 percent of respondents selected the response option "don't know." Finally, 2.5 percent of students did not respond to the question, and 0.7 percent provided responses that we judged uncodable. ${ }^{10}$

The ELS questionnaire includes a follow-up question, question 58 , for those who responded to the occupational plans prompt by listing a job: "How much education do you think you need to get the job you expect or plan to have when you are 30 years old?" Categories from "some high school" through "Ph.D." and "professional degree (such as J.D. or M.D.)" were then offered. To a limited extent, we used these responses to enhance our categorization of beliefs about the educational requirements of expected jobs. For the first and second groups in Table 2, we used the followup question to identify groups of respondents with potentially puzzling beliefs. As reported in the third column of Table 2, 16.8 percent (i.e., 8.4 percent of 50.2 percent) of those who listed only jobs that required a college degree or more (according to the O*NET) reported on the ELS questionnaire that they did not need a college degree to "get the job" they expected to occupy at age 30 . In the other direction, 83.5 percent (i.e., 12.9 percent of 15.4 percent) of those who listed jobs that required only a high school diploma (again, according to the O*NET) reported on the ELS questionnaire that they needed more than a high school diploma to "get the job.",11

As we discuss later, these categories of seemingly misaligned responses are not necessarily indicators of a lack of information or incorrect beliefs. We cannot, for example, rule out the possibility that some of the occupations for which O*NET specifies that a college degree is required include graded levels of jobs, some of which do not require a college degree. Furthermore, we cannot know how all respondents interpreted the "get the job" part of the question, with perhaps some believing correctly that even if a job formally requires only a high school diploma, a college degree is necessary to "get the job" over competitors in the local labor market.

Before we assess the explanatory power of this new measure, it is worth noting that even though these are the actual educational requirements of jobs listed by respondents, the educational requirements are pegged to students' beliefs about what "job or occupation" they "expect or plan to have at age 30." It is generally assumed in the literature that occupational plans are determined to some degree by students' beliefs about the level of education they feel they can acquire before the age of 30 . Accordingly, it would be incorrect to regard these beliefs as necessarily accurate indicators of their true occupational preferences, because for many students, occupational plans are "leveled" by their more encompassing beliefs about the openness of both educational institutions and the occupational opportunity structure.

\section{Beliefs and College Entry Patterns}

In this section, we address our primary research questions: (1) Do beliefs about the educational requirements of expected jobs, and any inherent uncertainty within these beliefs, predict college entry patterns? (2) Do beliefs about educational requirements predict college entry patterns after conditioning on family background?

Question I. Table 3 presents baseline associations between beliefs about the educational requirements of expected jobs and college entry patterns. To facilitate interpretation, we have ordered and grouped the rows of the table into four categories. The "certain and correct" category contains respondents who list only jobs that require a college education or more and who stated in the follow-up question that they believed that their expected job(s) require a college degree or more. This group of students has the highest observed college entry rates, with 87 percent entering college. Among those who enter, 91 percent do so within six months of high school graduation, and 69 percent attend four-year colleges. In contrast, the other "certain and correct" group - those who only list jobs that require no more than a high school degree and who believe that their planned occupations require no more than a high school degree - have the lowest college entry rate, with only 28 percent entering college. Among those who enter college, only 64 percent enter within six months of high school graduation, and 36 percent attend fouryear colleges. 
Table 3. Beliefs about the Educational Requirements of Expected Jobs and Subsequent College Entry Patterns

\begin{tabular}{|c|c|c|c|}
\hline \multirow[b]{2}{*}{$\begin{array}{l}\text { Beliefs about the Educational } \\
\text { Requirements of Expected Jobs }\end{array}$} & \multirow[b]{2}{*}{$\begin{array}{c}\text { Entered } \\
\text { College by } 2006\end{array}$} & \multicolumn{2}{|c|}{ Among College Entrants } \\
\hline & & $\begin{array}{l}\text { Entered within Six Months of } \\
\text { High School Graduation }\end{array}$ & $\begin{array}{l}\text { Entered a Four- } \\
\text { year College }\end{array}$ \\
\hline \multicolumn{4}{|l|}{ Certain and correct } \\
\hline College or more & $87 \%$ & $91 \%$ & $69 \%$ \\
\hline High school or less & $28 \%$ & $64 \%$ & $36 \%$ \\
\hline \multicolumn{4}{|l|}{ Uncertain but specific } \\
\hline High school and college & $76 \%$ & $83 \%$ & $51 \%$ \\
\hline \multicolumn{4}{|l|}{ Uncertain } \\
\hline "Don't know" & $66 \%$ & $85 \%$ & $55 \%$ \\
\hline \multicolumn{4}{|l|}{ Certain but possibly incorrect } \\
\hline $\begin{array}{l}\text { Expected job requires a high } \\
\text { school degree or less, but the } \\
\text { student believed college is } \\
\text { required }\end{array}$ & $63 \%$ & $79 \%$ & $38 \%$ \\
\hline $\begin{array}{l}\text { Expected job requires a college } \\
\text { degree or more, but the stu- } \\
\text { dent believed only a high } \\
\text { school degree is required }\end{array}$ & $57 \%$ & $79 \%$ & $24 \%$ \\
\hline \multicolumn{4}{|l|}{ Other } \\
\hline Missing & $54 \%$ & $83 \%$ & $46 \%$ \\
\hline Uncodable & $51 \%$ & $79 \%$ & $53 \%$ \\
\hline
\end{tabular}

Source: Education Longitudinal Study, 2002 to 2006.

Note: Data are weighted.

All other groups in the table have college entry patterns that fall between these two groups. Our "uncertain but specific" category consists of those who have specific jobs in mind but can be considered uncertain because their listed jobs require varying levels of education. For these students, 76 percent enter college. Among those who enter, 83 percent do so within six months, and 51 percent attend four-year colleges.

Our "uncertain" category consists of those who selected "don't know" in response to the occupational plans prompt. These students are clearly uncertain about the educational requirements of their expected future jobs, although this uncertainty is, to some degree, a by-product of uncertainty in planned occupation at age 30 . The results in Table 3 suggest that this group is much less likely to enter college than the "college or more" group, at only 66 percent. Of those who do enter college, 85 percent enter college immediately and 55 percent enter four-year colleges, comparable percentages to those of the "uncertain but specific" students.

Our final substantive category contains two "certain but possibly incorrect" groups. Of those who expected jobs that required only a high school diploma, yet who also reported that postsecondary education was necessary to "get the job" they expected to occupy, 63 percent enter college. Among the college entrants, 79 percent enter college without delay, but only 38 percent enter four-year colleges. The converse group - those who listed jobs for which the $\mathrm{O}^{*}$ NET database indicated that a college degree or more was required, but who responded that a college degree was not necessary to get the job - had a comparatively low rate of college entry, at only 57 percent. Although the rate of immediate entry among entrants is the same at 79 percent, only 24 percent of these respondents attend four-year colleges, the lowest rate in the entire sample.

We do not attach any interpretations to the respondents classified as missing and uncodable, here or for the remainder of this article. These two groups constitute only 3.2 percent of the sample, and we simply note that they have a profile entirely consistent with a moderately at-risk subpopulation. On all three dimensions of college entry analyzed here, they are below the mean 
transition rates, especially for our baseline college entry measure, at 54 and 51 percent compared with the sample mean of 72.5 percent.

Overall, the results presented in Table 3 suggest three basic conclusions, all of which support an answer of "yes" to our first research question. First, and as implied by decades of prior research but never directly shown (as far as we are aware), the higher the belief about the level of education required for an expected job, the more likely a student is to carry on to college, to enter college immediately after high school, and to find their way to an institution that grants bachelor's degrees. Second, students who maintained two or more specific occupational plans with inconsistent required levels of education were less likely to enter college, to do so immediately, or to enroll in a four-year college. Third, those who were unwilling to state an occupational plan but who were willing to indicate their uncertainty by selecting "don't know" were considerably less likely to enter college. But, among those who did enter, they were more likely than all but the always-college-or-more group to enter college immediately and, at some point, to enter a bachelor's degree granting institution.

Question 2. The baseline associations just presented imply that beliefs, and the different patterns of information on which they are based, may be an important determinant of college entry. Can these associations be explained away by simple family background, school sector, and demographic characteristics? If so, the associations reported in Table 3 can be understood as a simple mediating mechanism for the effects of these more fundamental variables. Information and beliefs would not necessarily have explanatory power as a contingent mechanism that carries forward a broad set of effects, including but not limited to those that are related to the fixed characteristics of family background.

To assess this possibility, Table 4 presents logit models for each of the three dimensions of college entry from Table 3, with and without adjustments for family background and other characteristics. Consider first models 1, 3, and 5, which are logit models that parameterize the baseline associations reported in Table 3. The reference category is the "certain and correct" group of "college or more," which was presented earlier as the group in the first row of Table 3. For the models in Table 4, dummy variables are specified for all other groups defined by the rows of Table 3 .
For each model, the coefficients are high multiples of their standard errors in all cases, suggesting that the sizable differences reported in Table 3 are also statistically significant when the reference group is "college or more." Of particular interest are the comparisons between the reference group and the "high school and college" category and between the reference group and the "don't know" category. The "high school and college" and "don't know" students have the most uncertain beliefs about their futures, whether because they lack available information or because of other effects, possibly structural, that inhibit the processing of available information. The 11 percent and 21 percent differences in entry rates, calculable from the first column in Table 3, correspond to logit coefficients of -0.73 and -1.23 in model 1 in Table 4. With standard errors of 0.19 and 0.07 , respectively, these differences are statistically significant by conventional standards.

Models 2, 4, and 6 then reestimate these three models, adjusting for 26 variables that measure family background, related demographic characteristics, and school sector. Means and standard deviations for these adjustment variables are presented in Appendix Table A1. Overall, the adjusted models fit the data better, as shown by the $\chi^{2}$ test statistics. More important, the coefficients for group differences in beliefs decline rather modestly after these covariates are added to the models. For example, the uncertain but specific group, "high school and college," has an adjusted college entry coefficient that declines in magnitude from -0.73 in model 1 to -0.54 in model 2 . The coefficients for patterns among entrants change even less when adjustment variables are fit, from -0.72 to -0.70 in models 3 and 4 (modeling delayed entry) and from -0.79 to -0.74 in models 5 and 6 (modeling four-year college entry). The pattern of decline for the "don't know" group is very similar. Thus, while the covariates are clearly important predictors of college entry patterns, they cannot account for the quite strong associations between beliefs and college entry present in models 1,3 , and 5 .

In sum, the results presented in Table 4 yield an answer of "yes" to our second empirical question. Net of adjustments for family background, demographic characteristics, and school sector, students who expect jobs that require a college education and who recognize that their expected jobs require a college education have the highest rates of college 


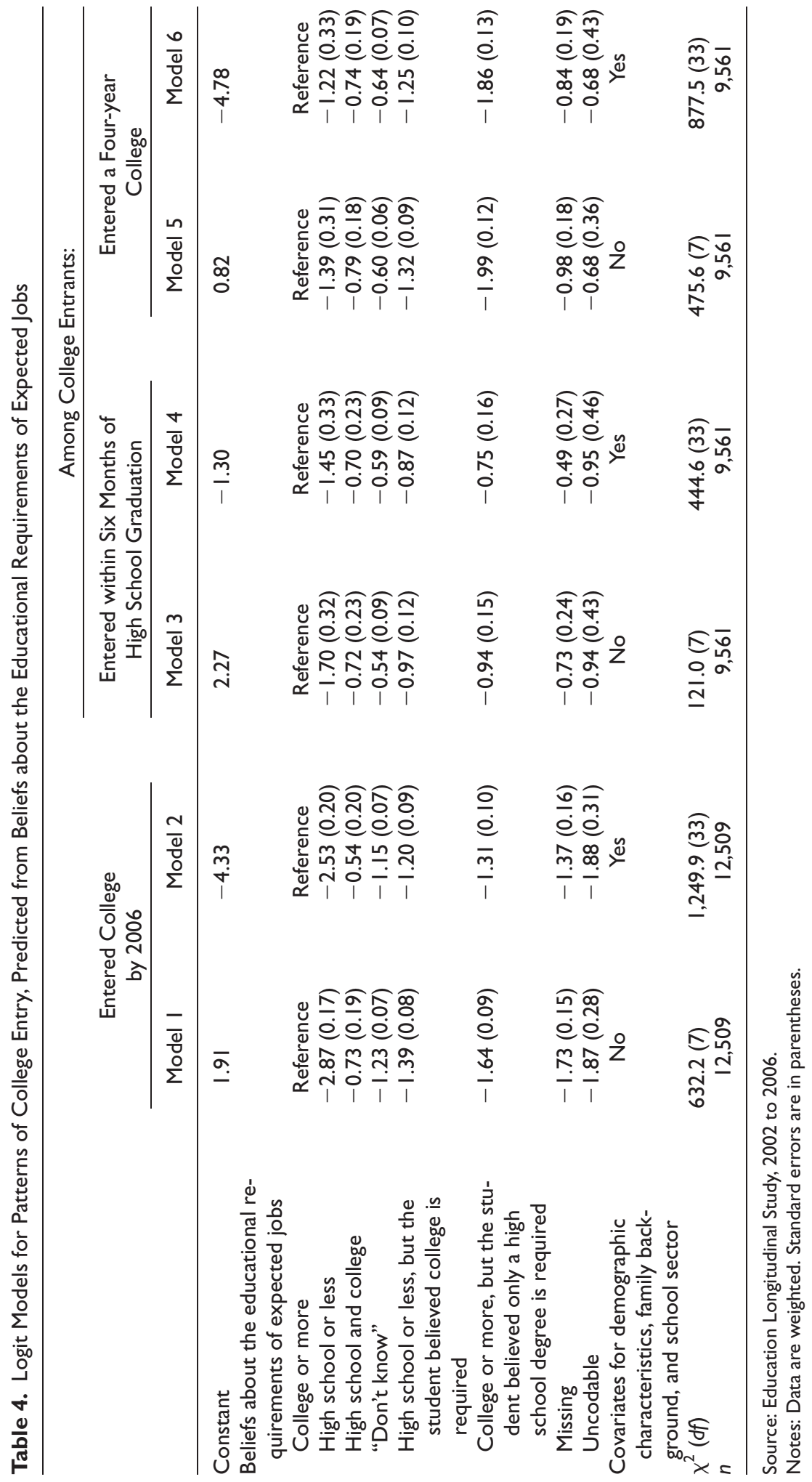


entry, immediate college enrollment, and attendance at four-year colleges. Students with settled beliefs at the opposite end of the spectrum have correspondingly low levels of college entry, immediate college entry, and four-year college attendance.

Although these two groups have trajectories that are easily explained by classic models of educational attainment, these two groups account for less than half of all high school seniors in the nation. In contrast, a full 52.5 percent of the nationally representative ELS sample has beliefs about the educational requirements of their futures jobs that are uncertain and/or possibly inaccurate. This group includes those who "don't know" their future jobs, those who have puzzling beliefs about the educational requirements of the specific jobs they expect to hold, and those who have internally contradictory occupational plans. In comparison to students who expect to have jobs that require a college education and who recognize that their expected jobs require a college degree, this three-part group of uncertain and possibly uninformed students is substantially less likely to enter college, to do so immediately after high school graduation, and to attend a fouryear college.

\section{Confounders, Heterogeneity, Foresight, and Performance}

The affirmative answers to our two primary questions suggest four secondary questions:

Question 3: Are the adjustments for family background and other characteristics sufficient to rule out the claim that a more comprehensive measure of family background might "explain away" the conditional associations reported for models 2,4 , and 6 in Table 4?

Question 4: Are the categories of "don't know" and "high school and college" heterogeneous in ways that undermine a claim that their members have substantial uncertainty in their beliefs?

Question 5: Are the apparent effects of uncertainty and information regarding educational requirements foreseen by students themselves, such that they can be explained away by students' own college expectations?

Question 6: Can these associations be partially accounted for by differences in performance at the end of high school, as implied by the recent literature on college entry that predicts that those with uncertain beliefs about the future will have less commitment to performance in schooling?

Questions 3 and 4. It is impossible to completely rule out the implicit hypothesis in question 3 that the estimated conditional association between beliefs about educational requirements and college entry can be entirely accounted for by a more complete measure of family background. This is, of course, a generic problem of observational data analysis and one to which there is no entirely definitive solution. We can, however, examine how serious the omitted variable bias threat is by examining whether the estimated effects covary with differences in the measures of family background that we are able to include in our models. If so, then the estimated conditional associations may simply be picking up the effects of unmeasured dimensions of family background (e.g., family wealth) related to those already in the model. If not, and the estimated effects are not patterned by our measures of family background, then a more comprehensive measure of family background could only "explain away" the associations in Table 4 if it, or some portion of it, were linearly unrelated to parents' education, family income, and the other variables presented in Table A1.

An analysis of this sort has the added pay-off of allowing us to address question 4 , which asks whether there is meaningful heterogeneity within our two groups of primary theoretical interest. Consider the "don't know" group. As we showed earlier, this group is considerably less likely to enter college than those who listed some jobs that required a college degree or more (i.e., both the "college or more" and the "high school and college" groups); however, if they enter college, students in this group are more likely than students in the "high school and college" group to enter immediately and to attend four-year colleges. One possible explanation for this pattern is that the "don't know" group consists of two very different types of students: (1) at-risk students from disadvantaged family backgrounds who do not have occupational plans and (2) advantaged students who are certain that they will go to college but are unwilling to pick from among a menu of high status jobs that they feel they are likely to occupy (i.e., they choose to respond as "don't know" rather than list "doctor or lawyer"). The students 
Table 5. Estimates of Consequential Heterogeneity for the "Don't Know" Group and the "High School and College" Group for the Model of College Entry

\begin{tabular}{llr}
\hline & \multicolumn{2}{c}{ Counterfactual Comparison Groups } \\
\cline { 2 - 3 } & College or More & High School or Less \\
\hline Observed "don't know" & & \\
Unadjusted difference (model I) & $-0.208(0.012)$ & $0.387(0.034)$ \\
Weighted to the "don't know" group & Balance $=0.071$ & Balance $=0.140$ \\
& $-0.185(0.013)$ & $0.326(0.045)$ \\
Weighted to the comparison group & Balance $=0.005$ & Balance $=0.050$ \\
& $-0.159(0.012)$ & $0.259(0.035)$ \\
$n$ & Balance $=0.007$ & Balance $=0.005$ \\
Observed "high school and college" & & 3,928 \\
Unadjusted difference (model I) & 9,224 & \\
Weighted to the "high school and & & $0.489(0.045)$ \\
college" group & $-0.106(0.033)$ & Balance $=0.133$ \\
Weighted to the comparison group & Balance $=0.100$ & $0.397(0.056)$ \\
& $-0.075(0.034)$ & Balance $=0.037$ \\
$n$ & Balance $=0.010$ & $0.329(0.075)$ \\
& $-0.056(0.028)$ & Balance $=0.122$ \\
\hline
\end{tabular}

Source: Education Longitudinal Study, 2002 to 2006.

Note: Data are weighted. Standard errors are in parentheses. The values reported for "balance" are the mean of the standardized means for the 26 variables entered as adjustment variables for model 2.

in group 1 are presumably unlikely to enter college, and once they are "cleared out" from among those who enter college, the residual group of students (group 2) is then presumably quite similar to the students in the "college or more" group.

Table 5 presents models that test for heterogeneity of effects within models 1 and 2 in Table 4, using a diagnostic routine based on estimated propensity scores (Morgan and Todd 2008). The goal of this matching strategy is to consider how the estimated difference in college entry rates changes as the model is weighted alternatively toward the profiles of each of two comparison groups.

We explain how this routine can be used in this section. For readers uninterested in the methodology, we can state the main conclusion now: On the basis of the results in Table 5 (and reported more completely in Tables S2 through S4 in the Supplementary Appendix, available at soe.sagepub.com), there is no compelling evidence that heterogeneity within the two groups characterized as having uncertain beliefs is consequential. There appears to be no support for the existence of either unmeasured confounders related to family background or a more complex compositional story about these groups that inhibits our interpretations on the basis of uncertainty of beliefs. Our answers to questions 3 and 4 are therefore "very probably yes" and "no," respectively.

Our analytic strategy is to make targeted comparisons for the initial college entry decision across the two groups of central theoretical interest, the "don't know" group and the "high school and college" group. The analysis is reported separately in the two panels of Table 5. We then compare these two groups with the two comparison groups with the cleanest available interpretations, the "high school or less" and "college or more" groups. Analyses that use these two comparison groups are presented separately in the two columns of each panel of Table 5. We use estimated propensity scores to match our two "treatment" groups ("don't know" and "high school and college") to two different control groups ("college or more" and "high school or less"), yielding four sets of estimates for the four corresponding comparisons. 
Within each of these comparisons, we estimate three mean differences in college entry rates. Consider the first column within the first panel of Table 5. For this comparison, we limit our analysis to the 9,224 students who are in the "don't know" group and the "college or more" group. The observed mean difference in the college entry rate of these two groups is -0.208 , which is the difference in the predicted college entry rates from model 1 in Table 4 and also the mean difference reported in Table 3 ( 0.87 vs. 0.66 in the first column). The standard error of the difference is 0.012 (see Table 5), suggesting that the mean difference is statistically significant. ${ }^{12}$

To probe for consequential heterogeneity, we estimate a logit model to predict inclusion in the treatment group of "don't know" relative to "college or more," where the predictor variables are the same 26 adjustment variables used in the models reported in Table 4 (and summarized in Table A1). Following iterative respecification of the logit model to improve balance, we construct two weights on the basis of the estimated propensity scores from these models, which are then used as weights in the original regression. The unadjusted difference is reestimated twice by aligning the data with the conditional distribution of the 26 variables, first as in the "don't know" group and then as in the "college or more" group.

Return now to the first column of the first panel of Table 5. The mean difference of -0.185 in the second row is the difference in college entry between the "don't know" group and the "college or more" group when the sample is aligned with the conditional distribution of the 26 variables for family background that characterize the "don't know" group. Likewise, the mean difference of -0.159 is the difference in the college entry rate but with the sample aligned with the "college or more" group. The difference between the two coefficients is -0.026 (i.e., $-0.185-[-0.159]=-0.026$ ). A difference of this size could have been produced by sampling error alone, because it is a difference between two other point estimates with standard errors of 0.013 and 0.012 , respectively. A substantive effect of 0.026 also represents either 14 percent or 16 percent of the underlying effect estimates (i.e., $0.026 / 0.185$ and $0.026 / 0.159$ ). This difference is, in our view, too small to support the hypothesis that the "don't know" category is composed of two qualitatively different subgroups of respondents, with respect to these 26 variables.

Analyses of the same structure are then performed for the other three comparisons in Table
5. The point estimates of mean differences move around, and the ability of the underlying logit to remove the imbalance through weighting varies with sample sizes. Nevertheless, the models tell essentially the same story: There is no substantial evidence of consequential heterogeneity.

In sum, then, these results (including the additional models reported in Tables S2 through S4 in the Supplementary Appendix) are encouraging for the predictions that motivate this article, offering answers of "very probably yes" for question 3 and "no" for question 4. Students who fall into the "don't know" or "high school and college" group do not appear to be internally heterogeneous in ways that would render our interpretations overly reductive.

It is less clear, perhaps, why these results are relevant to the "unobserved confounder" counternarrative that would suggest, for example, that the "don't know" group is simply an ipso facto proxy for lower socioeconomic status that could, in theory, be measured by additional family background variables. The logic of our position, however, is quite simple. Were such variables important, they would be directly related to our measured family background variables: Consider, for example, family wealth, an unmeasured family background variable that is known to be correlated with our measured family background variables. If the counternarrative were true, the effects would be substantially stronger when the two-way comparisons in Table 5 are weighted toward the groups with lower average levels of socioeconomic status. Under this weighting, the counternarrative would predict the strongest effects of the conjectured omitted variables, because their effects cumulate at the bottom of the distribution of measured family background. Overall, however, the differences are quite modest, and the effects are only sometimes in the direction consistent with the counternarrative. ${ }^{13}$

Question 5. Are these effects foreseen by students? In particular, does a student's expectation for college entry explain away the crucial associations reported earlier?

Consider again our working model in Figure 2. So far we have argued that the apparently robust associations between the beliefs about the educational requirements of expected jobs and college entry patterns give support for the unobserved causal pathway from information and beliefs to college entry, where information and beliefs have sources independent of family background. Note, however, that in our working model, it is possible 
that this effect is carried directly to college entry by way of educational expectations. That is, students may (1) select an expected job, (2) expect to get the education required to enter it, and (3) get precisely that education. If so, then all of the causal variation in students' beliefs about the educational requirements in their expected jobs would be entirely absorbed by the classic college expectations variable of the Wisconsin model, leaving no room for the new literature on college entry to enhance existing explanations.

The results presented in Table 6 evaluate this possibility by adjusting our models by educational expectations. Because of the influence of status attainment research on its design, the ELS is rich with such variables. For college entry (see model $2 a)$, we construct a variable indicating whether a student expects to complete more than 12 years of education from ELS question 42: "As things stand now, how far in school do you think you will get?" For immediate college entry (model $4 a)$, we construct a variable indicating whether a student expects to enter postsecondary education immediately after high school from question 45 , "Do you plan to go on to school right after high school?" Finally, for attendance at a four-year college (model 6a), we construct a variable (from question 42) that indicates whether a student expects to complete 16 or more years of education.

The coefficients in models $2 \mathrm{a}, 4 \mathrm{a}$, and $6 \mathrm{a}$ reported in Table 6 are directly comparable with those for models 2, 4, and 6 reported in Table 4, differing only in that the coefficients in Table 6 are based on models that include additional adjustment variables. For now, consider only models $2 \mathrm{a}, 4 \mathrm{a}$, and $6 \mathrm{a}$. In these models, the reference group for each of the expectations dummy variables is the group of students who expected to make the educational transition indicated by the dependent variable (e.g., enter college, enter immediately, enroll in a 4-year college). The two dummy variables are then "no" for those who did not expect to make the transition, and "missing" for those who did not respond to the particular expectations question.

As one would anticipated on the basis of prior research, educational expectations are strongly predictive of our three measures of college entry patterns. The expectations coefficients are large, and the overall model fit soars with a loss of only two degrees of freedom. More critical, for our purposes, is that although the associations between perceived educational requirements and each outcome decline, in most cases the decline is modest and in no case is more than half. For example, the estimated coefficients for the category "high school and college" decline from -0.54 to -0.52 (college entry; compare models 2 and $2 \mathrm{a}$ ), -0.70 to -0.66 (immediate entry conditional on entry at any time; compare models 4 and $4 \mathrm{a}$ ), and -0.74 to -0.44 (four-year college attendance conditional on entry; compare models 6 and 6a). A similar pattern obtains for the "don't know" category.

The associations between students' beliefs about the educational requirements of expected jobs and their college entry patterns thus cannot be explained away by students' foresight. Our answer to question 5 is therefore "no." The apparent effects of uncertainty and inaccuracy cannot be attributed to the master variable of status attainment theory, students' own college plans. This result strengthens our claim that the effects are both important and not already captured by what is inarguably the most influential model of educational attainment in the sociological literature. Moreover, it suggests a sixth and final empirical question.

Question 6. The recent literature on college entry that gives a prominent role to uncertainty of beliefs suggests that those with uncertain beliefs about their futures are less likely to demonstrate commitment to high performance in schooling. Do performance differences account for a substantial portion of the remaining associations?

To assess this question, we fit models that include the two measures of academic performance available in the 2004 ELS, a standardized test score in mathematics and cumulative grade point average by the 12th grade (see Table A1 for descriptive statistics on these two variables). These models (models $2 b, 4 b$, and $6 \mathrm{~b}$ in Table 6) include all of the others predictors present for models $2 \mathrm{a}, 4 \mathrm{a}$, and $6 \mathrm{a}$, including family background differences, school sector, and the relevant expectation for the dependent variable.

These final three models show that both measures of performance are strong predictors of college entry patterns, net of each other and of the many other variables in the models, and their coefficients are high multiples of their standard errors. ${ }^{14}$ An increase of one standard deviation of the math test score is equivalent to a net increase in the 


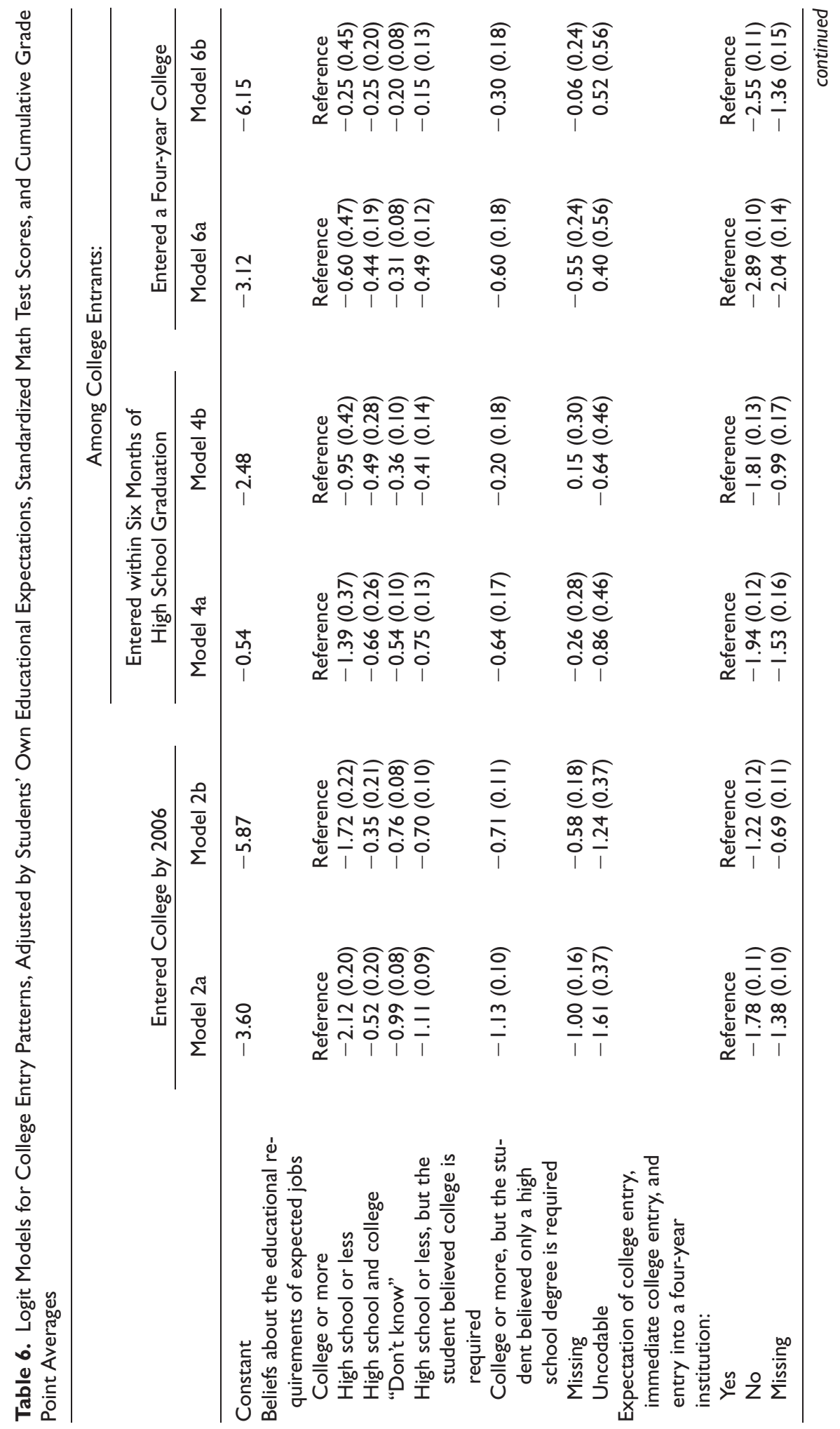




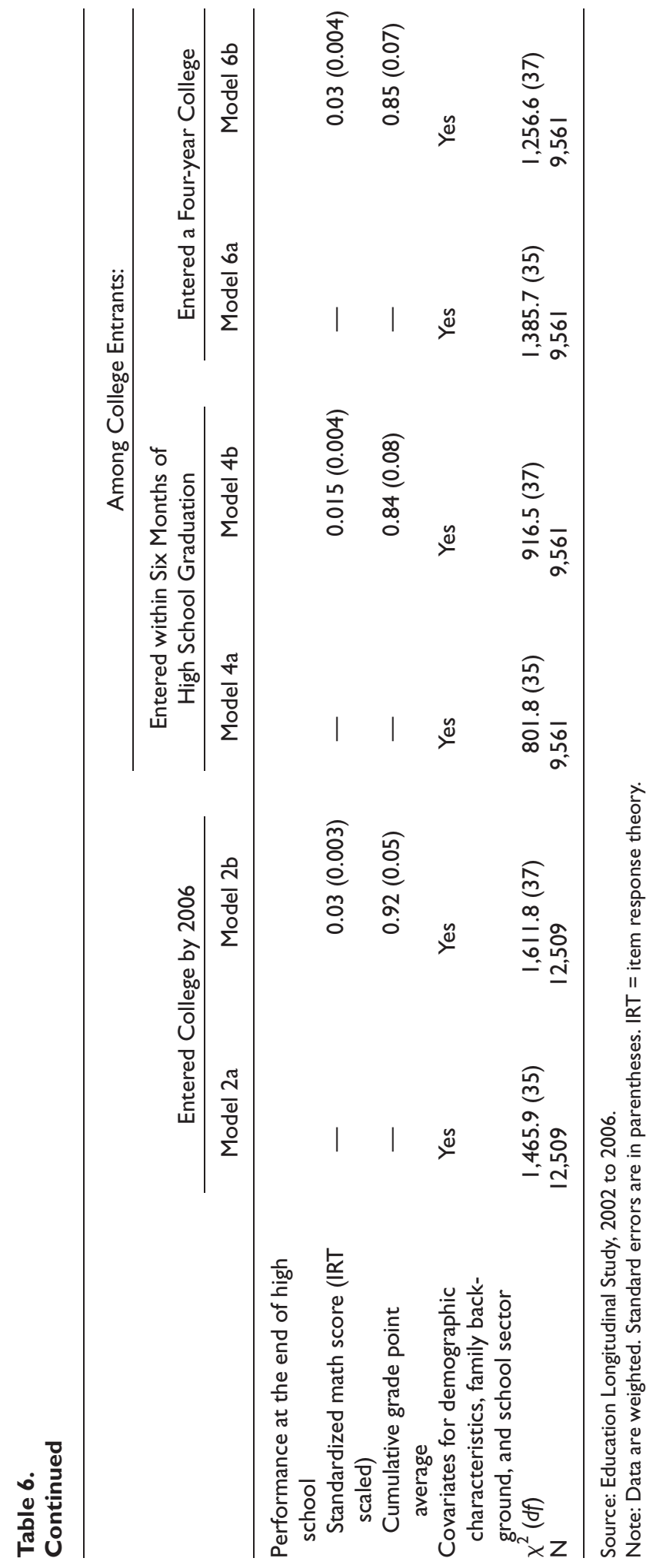


relevant $\log$ odds of 0.45 (college entry), 0.23 (immediate entry conditional on college), and 0.45 (four-year college conditional on college). An analogous one standard deviation increase in grade point average is equivalent to a simultaneous net increase in the relevant $\log$ odds of $0.80,0.73$, and 0.74 across the three models.

The remaining associations between perceived educational requirements and each outcome decline to some extent, consistent with the recent literature. The coefficients for the category "high school and college" decline from $-0.52,-0.66$, and -0.44 in model $2 \mathrm{a}$ (college entry), model $4 \mathrm{a}$ (immediate entry), and model 6a (four-year college) to $-0.35,-0.49$, and -0.25 in models $2 b$, $4 \mathrm{~b}$, and $6 \mathrm{~b}$, respectively. The first two coefficients in the performance-adjusted models fall just below conventional levels of statistical significance, and the third is only slightly larger than its standard error. A similar pattern holds for the coefficients for the "don't know" category, although all three of these coefficients remain statistically significant.

Our answer to question 6 is therefore "yes, but with important caveats." These final three models show that a student's performance at the end of high school, as measured by standardized tests and grades, can account for some of the remaining associations between beliefs and college entry patterns (even in the presence of supplemental adjustments for family background, school sector, and students' own forecasts of the dependent variable of each model). Uncertain and/or inaccurate beliefs about one's future may lead to performance declines in high school (see also Morgan et al. 2012), which then have effects on subsequent college entry decisions that are unforeseen by students when forming their educational expectations while still in high school.

At the same time, models $2 \mathrm{~b}, 4 \mathrm{~b}$, and $6 \mathrm{~b}$ also show that some of the effects of uncertainty and inaccuracy are not expressed in prior performance, nor are they reflected in lowered educational expectations. As a result, a small (and sometimes nonsignificant) portion of the total effects of uncertainty and inaccuracy unfold only after students complete high school and approach a concrete decision of whether to enroll in college. It may be that these students come to recognize that their occupational plans are insufficiently aligned with the educational choices that they confront (see also Schneider and Stevenson 1999). Forgoing college, delaying entry, or choosing to start at a community college may become more attractive when actual enrollment decisions must be made.

\section{CONCLUSIONS}

We have assumed that students' beliefs about their future jobs are part of a constellation of beliefs that include, among other components, crucial beliefs about whether a college degree is attainable and worthwhile given (perceived) constraints. A recent literature on college entry maintains that many high school students who do not continue on to college have educational and occupational plans that are grounded on underlying beliefs that are uncertain, inaccurate, or both. In this article, we bring new measures and models to bear to systematically evaluate this prediction.

We have shown that there are three profiles of such students, which together constitute more than half (52.5 percent) of a nationally representative sample of high school seniors:

1. Some students have fixed and specific beliefs about their educational and occupational futures, but their beliefs about the educational requirements of their planned jobs are, to an outside observer, best interpreted as inaccurate.

2. Some students are uncertain enough about their educational and occupational futures that they cannot specify an expected job. Their occupational uncertainty may be generated by a lack of information about the education system and pathways into the labor market. For some of these students, it may also emerge from the frustration of not knowing whether college is possible for them, on the basis of their perceptions of its costs and the likelihood that resources will be available to fund a college career to its conclusion.

3. Some students are able to specify jobs, but they are so uncertain about their educational futures that they choose multiple possible jobs that have divergent educational requirements. These students are not necessarily uninformed, or lacking in specific plans for their futures. Yet to an outside observer, they must be regarded as very uncertain about their futures, insofar as they are willing to state a menu of job expectations that is 
internally variable along the fundamental dimension of educational requirements.

These three groups of students are identified by our measured variable, beliefs about the educational requirements of expected jobs, which in our working model in Figure 2 overlays both general beliefs, $B$, and the seemingly objective variable, educational requirements of expected jobs. Accordingly, our measured variable identifies particular groups of individuals that differ on these underlying latent constructs. It is a valid indicator of some of the causal variation that travels along the two crucial paths, $Z \longrightarrow I \longrightarrow B \longrightarrow P \longrightarrow$ College Entry and $V \longrightarrow I \longrightarrow B \longrightarrow P \longrightarrow$ College Entry. This variation and its causal effects are core features of the recent literature on college entry that posits substantial effects of uncertainty and inaccuracy of students' beliefs.

In our analysis, we have shown that our measured variable for beliefs is a substantial predictor of college entry patterns, supporting the position that information, $I$, and general beliefs, $B$, carry forward the more fundamental effects of family background, $V$, and $Z$. Furthermore, because the association between our measured variable for beliefs and college entry cannot be attributed to family background (or likely any additional unmeasured variables that are linearly related to family background), it is reasonable to conclude that our measured variable for beliefs carries forward some of the effects of information, $I$, that we assume have exogenous sources in $Z$ and are independent of family background.

Finally, we have shown that relatively little of the association between our measured variable for beliefs and college entry patterns can be explained away by students' own college expectations, suggesting that some of the future effects that generate the conditional associations with our measured variable for beliefs are unrecognized by students. These remaining associations, however, can to some extent be accounted for by differences in performance measured at the end of high school. Together, these final two results are consistent with the recent literature on college entry that gives a prominent explanatory role to the importance of uncertainty of students' beliefs about their futures. Not only are these beliefs presumed to have autonomous effects on ultimate decisions about college entry, they are also presumed to structure daily commitment decisions to performance in high school.

\section{APPENDIX}

Table A I. Means and Standard Deviations of Primary Variables

\begin{tabular}{|c|c|c|}
\hline Variable & M & $S D$ \\
\hline \multicolumn{3}{|l|}{$\begin{array}{l}\text { Race and gender (white and male } \\
\text { are the reference categories) }\end{array}$} \\
\hline White and female & 0.309 & \\
\hline Native American and male & 0.005 & \\
\hline Native American and female & 0.005 & \\
\hline Asian and male & 0.020 & \\
\hline Asian and female & 0.019 & \\
\hline Black and male & 0.071 & \\
\hline Black and female & 0.070 & \\
\hline Hispanic and male & 0.076 & \\
\hline Hispanic and female & 0.077 & \\
\hline Multiracial male & 0.023 & \\
\hline Multiracial female & 0.023 & \\
\hline \multicolumn{3}{|l|}{$\begin{array}{l}\text { Urbanicity (suburban is the ref- } \\
\text { erence category) }\end{array}$} \\
\hline Urban & 0.296 & \\
\hline Rural & 0.198 & \\
\hline \multicolumn{3}{|l|}{$\begin{array}{l}\text { Region (Midwest is the reference } \\
\text { category) }\end{array}$} \\
\hline Northeast & 0.181 & \\
\hline South & 0.348 & \\
\hline West & 0.224 & \\
\hline \multicolumn{3}{|l|}{$\begin{array}{l}\text { School sector (public is the ref- } \\
\text { erence category) }\end{array}$} \\
\hline Catholic & 0.044 & \\
\hline Other private & 0.034 & \\
\hline \multicolumn{3}{|l|}{$\begin{array}{l}\text { Family composition (mother- } \\
\text { father family is the reference } \\
\text { category) }\end{array}$} \\
\hline Mother-only family & 0.203 & \\
\hline Father-only family & 0.034 & \\
\hline Other family & 0.009 & \\
\hline \multicolumn{3}{|l|}{ Family background } \\
\hline Mother's education (years) & 13.57 & 2.34 \\
\hline Father's education (years) & 13.75 & 2.64 \\
\hline $\begin{array}{l}\text { SEl score of mother's occupa- } \\
\text { tion in } 2002 \text { (GSS } 1989 \\
\text { coding) }\end{array}$ & 45.51 & 13.02 \\
\hline $\begin{array}{l}\text { SEl score of father's occupation } \\
\text { in } 2002 \text { (GSS } 1989 \text { coding) }\end{array}$ & 44.70 & 11.85 \\
\hline Family income (natural log) & 10.66 & 1.08 \\
\hline \multicolumn{3}{|l|}{ Performance } \\
\hline $\begin{array}{l}\text { Standardized math test score } \\
\text { in } 2004 \text { (IRT scaled) }\end{array}$ & 47.5 & $|5.0|$ \\
\hline $\begin{array}{l}\text { Cumulative grade point } \\
\text { average }\end{array}$ & 2.62 & 0.87 \\
\hline
\end{tabular}

Source: Education Longitudinal Study, 2002 to 2006. Note: See Table 4 Data are weighted. GSS = General Social Survey; IRT = item response theory; SEI = Socioeconomic Index. 


\section{ACKNOWLEDGMENTS}

We thank Thomas Barnes, Shenell Bourne, Elissa Cohen, Catherine Pimentel, Amanda Pinto, and William Tannanbaum for their research assistance, as well as colleagues at Duke University, the University of Minnesota, The Ohio State University, Princeton University, and the University of Wisconsin for their enriching comments.

\section{FUNDING}

The authors disclosed receipt of the following financial support for the research, authorship, and/or publication of this article: This research was supported by grant SBES-1023798 from the National Science Foundation. The opinions are those of the authors and do not necessarily reflect those of the granting agency.

\section{NOTES}

1. For a sampling of recent reviews on the sociology of educational attainment, from alternative perspectives that demonstrate the vibrancy of the literature, see Breen and Jonsson (2005); Buchmann, DiPrete, and McDaniel (2008); Gamoran (2001); Grodsky and Jackson (2009); Kao and Thompson (2003); and Stevens, Armstrong, and Arum (2008).

2. Figure 1 represents a causal model in the new causal graph tradition (Pearl 2009; see Morgan and Winship 2007 for an introduction written for sociologists). In these models, typically labeled nonparametric structural equation models, the arrows signify inclusion in kernel functions $f($.) that generate effects and where no functional form is placed on the kernels. Thus, if $A$ and $B$ have arrows that point to $Y$, then the structural relation is specified as $Y=f_{Y}\left(A, B, e_{Y}\right)$, where the right-hand side can be parameterized variously, such as $a \times A+b \times \ln (B)+e_{Y}, a \times A+b \times B+c \times(A$ $+B)+e_{Y}$, or any other function in $A, B$, and $e_{Y}$.

3. Educational aspirations are measured in the original Wisconsin model articles with a variable for selfreported college plans.

4. The original 1969 Wisconsin model also did not allow family background to have a net direct effect on educational attainment, but nearly all subsequent work in this tradition has allowed for it.

5. It bears mentioning that we are agnostic about two issues. First, we do not take a position on how performance and family background jointly determine college entry: deliberate choice, conditioned action in response to significant others, or some other mechanism entirely. We also do not take a strong position on the two gray arrows in the figure. College expectations may be a direct cause of college entry, as in the Wisconsin model. The educational requirements of expected jobs may also be a direct cause of college expectations, as was entertained long ago by
Duncan et al. (1968) and, more recently, by Xie and Goyette (2003).

6. Because the data distributors did not create a full panel weight, we first multiplied BYF2WT by the estimated inverse probability of being in all three waves rather than only the base-year and second follow-up (i.e., the 12,591 respondents in all three waves who are a subset of the 13,390 respondents who participated in the base-year and second follow-up waves only). We then multiplied the resulting weight by the estimated inverse probability of being in the sample that includes full information on postsecondary attendance (i.e., the 12,509 respondents who are a subset of the 12,591 respondents who participated in all three waves). Exploratory analysis revealed, however, that the results of this study would be nearly exactly the same if the simpler BYF2WT were used instead of its elaboration. Apparently, those who participated in the base-year and second follow-up waves but not in the first follow-up wave are very similar to those who participated in all three waves of the survey. They were likely nonrespondents in the first follow-up wave because they were absent on the day of the survey, and in most cases for reasons unrelated to later educational attainment.

7. We define immediate college entry as having entered a postsecondary institution within six months of graduating from high school or receiving a General Educational Development certificate. However, after inspection of the data, for respondents who graduated well before or after their classes, we favored the data distributor's definition of immediate entry as entering college within the first available enrollment window. This stipulation counted five students who graduated early (but who did not enter college within six months of graduation) as immediate entrants and three students who graduated late (but who did enter college within six months of graduation) as delayed entrants.

8. According to the 2004 questionnaire, respondents had a fourth choice, "not planning to work at age 30." The raw data set that was produced by the data distributors indicated that no students selected this response. However, the same question in 2002 (sophomore year) elicited "not planning to work" responses from 0.8 percent of the sample. We suspect, on the basis of examination of the coding of the 17-category variable F1OCC 30 , that 99 respondents in 2004 actually chose "not planning to work at age 30 " but were coded by the data distributors as "item legitimate skip/NA."

9. To merge in the $\mathrm{O}^{*} \mathrm{NET}$ educational requirement information, we collapsed our 1,212 job codes (i.e., all but the single "uncodable" category for a verbatim response and 7 distinct codes for types of missingness) into 408 broader categories across which educational requirement information is made available in the $\mathrm{O}^{*} \mathrm{NET}$. 
10. The latter responses were either uninterpretable strings of characters (which we assume resulted from poor handwriting or transcription errors) or joke responses.

11. What about the other groups in Table 2? We ignored this question for the 2.0 percent of respondents who listed multiple jobs that required either a high school degree or less and a college degree or more. We could not see how to map the question back to the internally inconsistent set of jobs listed in a way that would help clarify the group, and we only had a weighted $n$ of 254.5 respondents in the group anyway. Likewise, the question was a legitimate skip for those who selected "don't know" as their occupational plan.

12. The balance statistic, 0.071 , is the mean of the standardized mean difference across all 26 covariates that are used to adjust the models in Table 4 (see equation 9 in Morgan and Todd 2008; for the specific covariates, see Table A1). Thus, the unadjusted difference for this comparison is associated with an underlying set of modestly imbalanced data, where the groups differ in family background and other characteristics.

13. For example, the association between "don't know" and college entry is stronger when weighted toward "don't know" rather than "college or more" (at -0.185 instead of -0.159 ). Yet the difference is also stronger when the association between "don't know" and college entry is weighted toward "don't know" rather than "high school or less," at 0.326 instead of 0.259 . The first difference is consistent with the counternarrative, but the second is not.

14. An intermediate set of models, which include performance but not expectations, was also fit to the data. Because educational expectations and performance covary, these models had larger estimated coefficients for performance. The sizes of the crucial "high school and college" and "don't know" categories were therefore more negative than for models $2 b, 4 b$, and $6 b$.

\section{REFERENCES}

Bozick, Robert, Karl L. Alexander, Doris Entwisle, Susan Dauber, and Kerri Kerr. 2010. "Framing the Future: Revisiting the Place of Educational Expectations in Status Attainment." Social Forces 88(5):2027-52.

Breen, Richard and Jan O. Jonsson. 2005. "Inequality of Opportunity in Comparative Perspective: Recent Research on Educational Attainment and Social Mobility." Annual Review of Sociology 31:223-43.

Buchmann, Claudia, Thomas A. DiPrete, and Anne McDaniel. 2008. "Gender Inequalities in Education." Annual Review of Sociology 34:319-37.

Comay, Y., A. Melnik, and M. A. Pollatschek. 1973. "The Option Value of Education and the Optimal
Path for Investment in Human Capital." International Economic Review 14(2):421-35.

Duncan, Otis Dudley, Archibald O. Haller, and Alejandro Portes. 1968. "Peer Influences on Aspirations: A Reinterpretation." American Journal of Sociology 74(2):119-37.

Gamoran, Adam. 2001. "American Schooling and Educational Inequality: A Forecast for the 21st Century." Sociology of Education 74(Extra Issue): 135-53.

Goyette, Kimberly A. 2008. "College for Some to College for All: Social Background, Occupational Expectations, and Educational Expectations over Time." Social Science Research 37(2):461-84.

Grodsky, Eric and Erica Jackson. 2009. "Social Stratification in Higher Education." Teachers College Record 111:2357-84.

Grodsky, Eric and Melanie T. Jones. 2007. "Real and Imagined Barriers to College Entry: Perceptions of Cost.' Social Science Research 36(2):745-66.

Grodsky, Eric and Catherine Riegle-Crumb. 2010. "Those Who Choose and Those Who Don't: Social Background and College Orientation." Annals of the American Academy of Political and Social Science 627:14-35.

Hoxby, Caroline M. 2004. College Choices: The Economics of Where to Go, When to Go, and How to Pay for It. Chicago: University of Chicago Press.

Kao, Grace and Jennifer S. Thompson. 2003. "Racial and Ethnic Stratification in Educational Achievement and Attainment." Annual Review of Sociology 29:417-42.

Keane, Michael P. and Kenneth I. Wolpin. 2000. "Eliminating Race Differences in School Attainment and Labor Market Success." Journal of Labor Economics 18(4):614-52.

Manski, Charles F. 1989. "Schooling as Experimentation: A Reappraisal of the Postsecondary Dropout Phenomenon." Economics of Education Review 8(4):305-12.

Manski, Charles F. and David A. Wise. 1983. College Choice in America. Cambridge, MA: Harvard University Press.

Morgan, Stephen L. 2005. On the Edge of Commitment: Educational Attainment and Race in the United States. Stanford, CA: Stanford University Press.

Morgan, Stephen L., Theodore S. Leenman, Jennifer J. Todd, and Kim A. Weeden. 2012. "Stutter-step Models of Performance in School." Ithaca, NY: Cornell University, Department of Sociology.

Morgan, Stephen L. and Jennifer J. Todd. 2008. “A Diagnostic Routine for the Detection of Consequential Heterogeneity of Causal Effects." Sociological Methodology 38(1):231-81.

Morgan, Stephen L. and Christopher Winship. 2007. Counterfactuals and Causal Inference: Methods and 
Principles for Social Research. Cambridge, UK: Cambridge University Press.

Pearl, Judea. 2009. Causality: Models, Reasoning, and Inference. Cambridge, UK: Cambridge University Press.

Schneider, Barbara L. and David Stevenson. 1999. The Ambitious Generation: America's Teenagers, Motivated but Directionless. New Haven, CT: Yale University Press.

Sewell, William H., Archibald O. Haller, and Alejandro Portes. 1969. "The Educational and Early Occupational Attainment Process." American Sociological Review 34(1):82-92.

Sewell, William H., Robert M. Hauser, Kristen W. Springer, and Taissa S. Hauser. 2004. "As We Age: A Review of the Wisconsin Longitudinal Study, 1957-2001." Research in Social Stratification and Mobility 20(1):3-111.

Staff, Jeremy, Angel Harris, Ricardo Sabates, and Laine Briddell. 2010. "Uncertainty in Early Occupational Aspirations: Role Exploration or Aimlessness?" Social Forces 89(2):659-84.

Stevens, Mitchell L., Elizabeth A. Armstrong, and Richard Arum. 2008. "Sieve, Incubator, Temple, Hub: Empirical and Theoretical Advances in the Sociology of Higher Education." Annual Review of Sociology 34:127-51.

Willis, Robert and Sherwin Rosen. 1979. "Education and Self-selection." Journal of Political Economy 87(5): S7-35.

Xie, Yu and Kimberly A. Goyette. 2003. "Social Mobility and the Educational Choices of Asian Americans." Social Science Research 32(3):467-98. 